\title{
Impact of aeration on macrophyte establishment in sub-surface constructed wetlands used for tertiary treatment of sewage
}

Eleanor Butterworth¹, Andrew Richards², Mark Jones², Hans Brix³, Gabriela

Dotro $^{1 *}$, Bruce Jefferson ${ }^{1}$

${ }^{1}$ Cranfield University, Cranfield, UK

2 Severn Trent Water, Coventry, UK

${ }^{3}$ Department of Bioscience, Aarhus University, Denmark

*corresponding author: g.c.dotro@cranfield.ac.uk

\begin{abstract}
The effect of artificial aeration on plant growth in constructed wetlands in terms of above and below ground biomass and nutrient uptake of two macrophyte species Phragmites australis and Typha latifolia was carried out to provide quantitative, mechanistic evidence to support any differences between the plant species establishment. Pilot scale systems were built and supplied with different intensities of aeration and corresponding controls, with supporting evidence from two full scale operational sites. Results show T. latifolia was more impacted by aeration than $P$. australis when comparing against their respective non-aerated controls, evidenced in reduced height, growth rate and leaf length. However, the impact was less visible due to T. latifolia's faster growth rate compared to $P$. australis. Micro and macronutrient uptake by each species had no discernible pattern, preventing the identification of a definitive mechanism to explain the retarded growth. However, results suggest a synergy between iron and manganese may be at play.
\end{abstract}


Keywords: aeration; plant development; reed beds; nutrients; biomass; wastewater.

\section{$1.0 \quad$ Introduction}

Constructed wetlands (CWs) by definition contain vegetation adapted to waterlogged conditions (Mitsch and Gosselink, 2000). The specific function of this vegetation in CWs has been much discussed in the literature (Brix, 1997; Stottmeister et al, 2003; Langergraber, 2005) with their importance primarily being attributed to seasonal storage of nutrients; extra surfaces for microbial growth (although this is small in comparison to the surface area of the gravel); insulation in cold and temperate climates, blocking wind and shading out algae that can lower re-aeration; carbon content of plant litter supplying energy for heterotrophic denitrifiers; promotion of wildlife / biodiversity; aesthetics and prevention of unwanted species colonizing the bed (Brix, 1997; Kadlec and Wallace, 2009). In screened sewage treatment systems in France, the reeds also contribute to keeping the beds aerated by breaking up the surface sludge layer in the first stage bed through wind-rock action (Knowles et al, 2011).

A recent innovation in horizontal sub-surface flow (HSSF) CWs has been the inclusion of forced aeration to promote aerobic conditions and ammonia removal (Ouellet-Plamondon et al, 2006; Zhang et al, 2010). This has proved successful in the US (Kadlec and Wallace, 2009) and testing is producing successful results in the UK (Butterworth et al, 2013) and Europe (Nivala, 2012). However, poor/nonestablishment of Phragmites australis has been reported at highly aerobic sites. 
For instance, during full scale trials of aerated horizontal sub-surface flow (HSSF) CWs, poor establishment of $P$. australis was observed in an artificially aerated HSSF CW compared to excellent growth in an identical non-aerated control (Butterworth et al, 2013). Additionally, poor growth/non-establishment of $P$. australis has been reported in the first growing season in the second half of a pilot aerated $\mathrm{CW}$ in Germany (Nivala, 2012). Similar issues with either yellowing of the leaves (chlorosis) and/or poor establishment of Phragmites australis has been reported in second stage vertical flow (VF) wetlands both in the UK and France (Weedon, 2014).

Consequent literature searches revealed a gap in the knowledge with respect to the response of the plants to forced aeration. Wetland plants have been adapted to grow in typically oxygen limited, slow flow conditions (Mitsch and Gosselink, 2000). Artificially aerating the environments, either by forced aeration or by rapid and strong pulses of flow injection (by pumps or siphons) as employed in VF systems, changes those conditions radically. The main changes could be grouped into biogeochemical, i.e., macro or micro nutrient deficiency caused by the aerobic environments leading to changes in redox states that can affect their bioavailability (Weedon, 2014); or mechanical, i.e., flow turbulence causing root destabilisation resulting in stress induced growth inhibition and/or water ingress into the aerenchyma preventing effective oxygen transfer to the roots. Additionally, it was discussed that the problem is possibly species specific, as species other than P. australis have been able to colonize the aerated environment. It was further noted that the species T. latifolia is commonly used in the US due to 
its competitive and aggressive nature; ability to colonize inert substrates and adapt to diverse and not always optimal climate conditions (Jesperson et al, 1998).

To date, discussion has been largely qualitative such that to the authors' knowledge a paucity of direct experimental evidence exists to help populate the discussion, limiting the potential to define mitigation strategies going forward. Accordingly, the aim of the current investigation was to provide an experimental assessment of the impact of aeration on plant health in terms of above and below ground biomass and nutrient uptake of two macrophyte species $P$. australis and $T$. latifolia. The main hypothesis were that aeration intensity reduces nutrient uptake and causes physical destabilisation of the root zone, both resulting in reduced plant establishment in aerated wetlands.

\section{$2 \quad$ Materials and Methods}

\subsection{Pilot studies}

Individual test microcosms were constructed utilising water butts (height $83 \mathrm{~cm}$, width $46 \mathrm{~cm}$, depth $45 \mathrm{~cm}$ - gardens4less.co.uk) fitted with an aeration pipe of 12 $\mathrm{mm}$ diameter irrigation pipe with a single $2 \mathrm{~mm}$ diameter orifice connected to the mains air supply to imitate conditions found in the aerated bed (Figure 1). The columns were filled $0.6 \mathrm{~m}$ deep with gravel of 6-12 mm diameter, and planted with a single plug plant (Reeds from Seeds, Denbighshire, UK; $10 \mathrm{~cm}$ pot size), as per standard Severn Trent Water reed bed design, and fed with partially treated wastewater (12.1-20.9 $\mathrm{mgNH}_{4}{ }^{+}-\mathrm{N} / \mathrm{L}$ and 184-300 $\mathrm{mgO}_{2} / \mathrm{L}$ for ammonium and chemical oxygen demand, COD, respectively) to $0.1 \mathrm{~m}$ below the gravel surface. A 
tap fitted to the bottom of the water butt allowed drainage and re-filling which took place every other day for the duration of the experiment. The composition of the wastewater on the feed and effluent of each reactor was tested three times throughout the study for $\mathrm{NH}_{4}{ }^{+}-\mathrm{N}$, nitrate $\left(\mathrm{NO}_{3}-\mathrm{N}\right)$ and nitrite $\left(\mathrm{NO}_{2}-\mathrm{N}\right)$ and COD with Hach-Lange test kits. The reactors were placed outside and were operated for the period May to August 2013. The temperatures during this period averaged $16^{\circ} \mathrm{C}$ (min $3^{\circ} \mathrm{C}$, $\max 30^{\circ} \mathrm{C}$ ) with $40.5 \%$ cloud cover recorded (records obtained from www.wunderground.com).

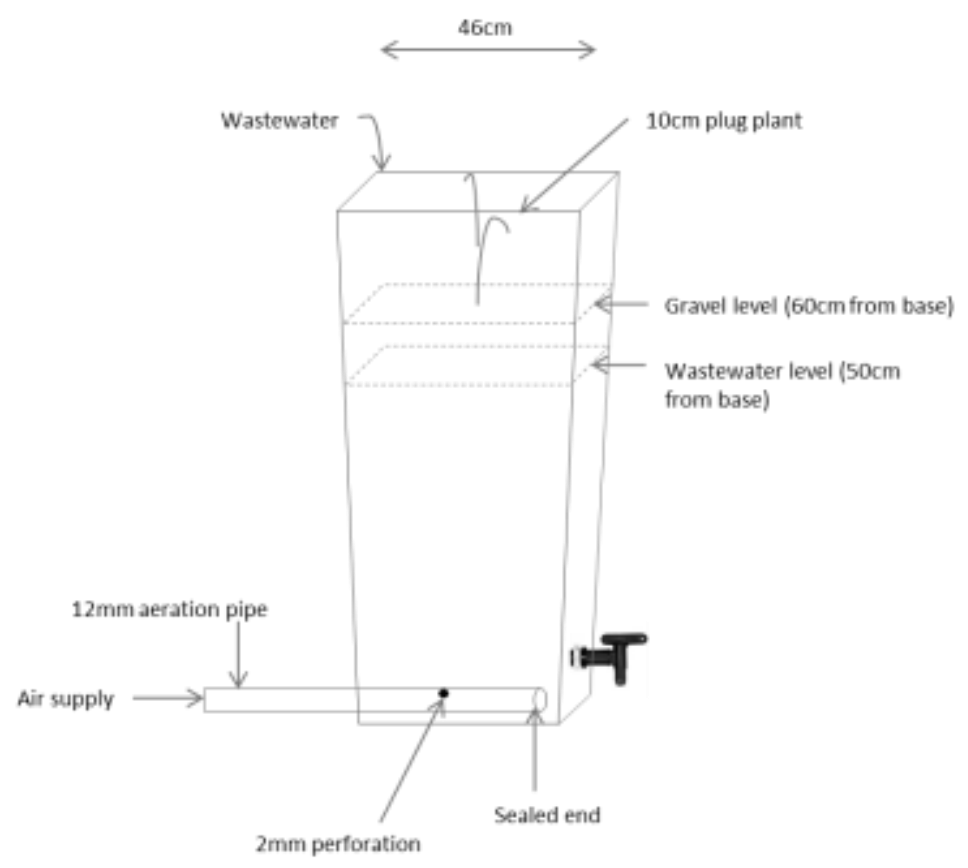

Figure 1 Pilot reactors

Two aeration rates were investigated. The first represented the equivalent rate used on an operational site (Site 2) defined as $150 \mathrm{~m}^{3} / \mathrm{h}$ of air delivered per $100 \mathrm{~m}^{2}$ of bed, corresponding to $2.3 \mathrm{~L} / \mathrm{min}$ per hole [defined as high]. The second was based on a separate study that determined the required air delivery rate to 
maintain aerobic environments as the operational rates above had been observed to exceed those actually required (Butterworth et al, in prep.). The reduced rate was $0.8 \mathrm{~L} / \mathrm{min}$ per hole [defined as low] and thus provided insight into whether optimised aeration could mitigate any observed impacts. Tests were carried out in triplicate and include a non-aerated control for each plant species (Figure 2).

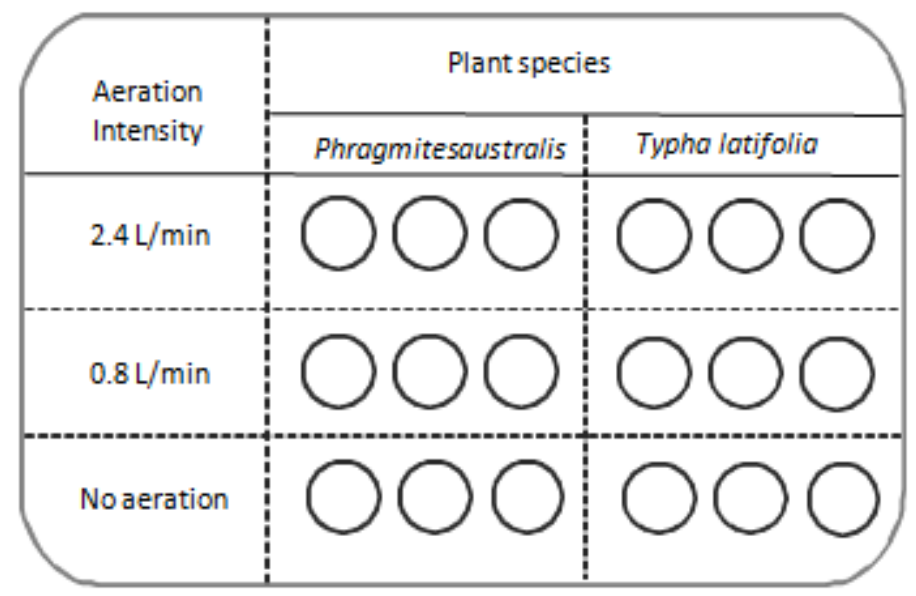

Figure 2 Variables tested in the pilot study

Direct observations were recorded during the growing period including plant height (measured from gravel level to the tip of the tallest stem); number of stems, leaf length (measured from the base to the tip) and leaf width (measured at the widest part). Harvesting took place four months after planting, at the end of the growing season. The plants were removed from the butts and any loose soil washed away. Visual differences were recorded in the roots and rhizomes including the presence of primary and lateral fine side roots, their number, diameter and length. In addition, butts were turned on their side at the end of the experiment to enable direct visual observation of any differences. Plants were then fractionated into roots and rhizomes (below-ground biomass) and above-ground 
biomass and dried at $70{ }^{\circ} \mathrm{C}$ until constant weight and cooled in a dry environment. Samples were then ground to $1 \mathrm{~mm}$ and dried further for use in nutrient analysis. Total nitrogen $(\mathrm{N})$ was analyzed by gas chromatography after combustion of ground plant material (Vario EL III Elementar Analyzer). Concentrations of phosphorus $(\mathrm{P})$, potassium $(\mathrm{K})$, sodium $(\mathrm{Na})$, calcium $(\mathrm{Ca})$, magnesium $(\mathrm{Mg})$, iron $(\mathrm{Fe})$, manganese $(\mathrm{Mn})$, copper $(\mathrm{Cu})$, zinc $(\mathrm{Zn})$ and nickel $(\mathrm{Ni})$ were determined by spectrometry (atomic absorption for $\mathrm{Na}, \mathrm{Ca}, \mathrm{Mg}, \mathrm{Fe}$ and $\mathrm{Ni}$; inductively coupled plasma for $\mathrm{K}, \mathrm{Mn}, \mathrm{Zn}$ and $\mathrm{Cu}$ using a Perkin Elmer Analyst 800 and Perkin Elmer ELAN 9000 system respectively, and P using UV/ VIS spectrophotometer Nicolet Evolution 100E) after extraction by a nitric/hydrochloric acid mixture and microwave digestion of $0.25 \mathrm{~g}$ of ground plant material. Standards were run prior to running samples and every 10 samples thereafter for all machines, plus two blanks for quality assurance.

\subsection{Full scale studies}

Site 1 contains two equally sized tertiary HSSF CWs of $56 \mathrm{~m} \times 12.5 \mathrm{~m}$ each. Artificial aeration was retrofitted in both beds during gravel cleaning and replacement (refurbishment) and one was planted with T. latifolia and one with $P$. australis (Figure 3). The hydraulic loading rate applied was $0.44 \mathrm{~m} / \mathrm{d}$, with typical influent concentrations of $387 \mathrm{mgO}_{2} / \mathrm{L}$ and $22 \mathrm{mgNH}_{4}{ }^{+}-\mathrm{N} / \mathrm{L}$. The mean temperatures during the study period March January 2012 to December 2013 were $9^{\circ} \mathrm{C}\left(-8^{\circ} \mathrm{C}\right.$ to $\left.29^{\circ} \mathrm{C}\right)$, with $63 \%$ cloud cover. Site 2 consisted of two tertiary treatment HSSF CWs, $10 \mathrm{~m} \times 10 \mathrm{~m}$ each, with a separate combined sewer overflow CW (Butterworth et al, 2013). Both beds in Site 2 were planted with P. australis and operated 
with an average hydraulic loading rate of $0.27 \mathrm{~m} / \mathrm{d}$ and treating wastewater with mean concentrations of $72 \mathrm{mgO}_{2} / \mathrm{L}$ and $11.5 \mathrm{mgNH}_{4}{ }^{+}-\mathrm{N} / \mathrm{L}$. Mean air temperatures at this works were $13^{\circ} \mathrm{C}\left(-3^{\circ} \mathrm{C}\right.$ to $\left.30^{\circ} \mathrm{C}\right)$, with $62 \%$ cloud cover. This site serves as a full scale control site whereby both beds were fitted with aeration; one was switched on in March 2011 and the other left dormant to provide a control. Both sites were maintained and operated according to Severn Trent guidelines, i.e., periodic inlet cleaning without plant harvesting or any other interventions during this study.

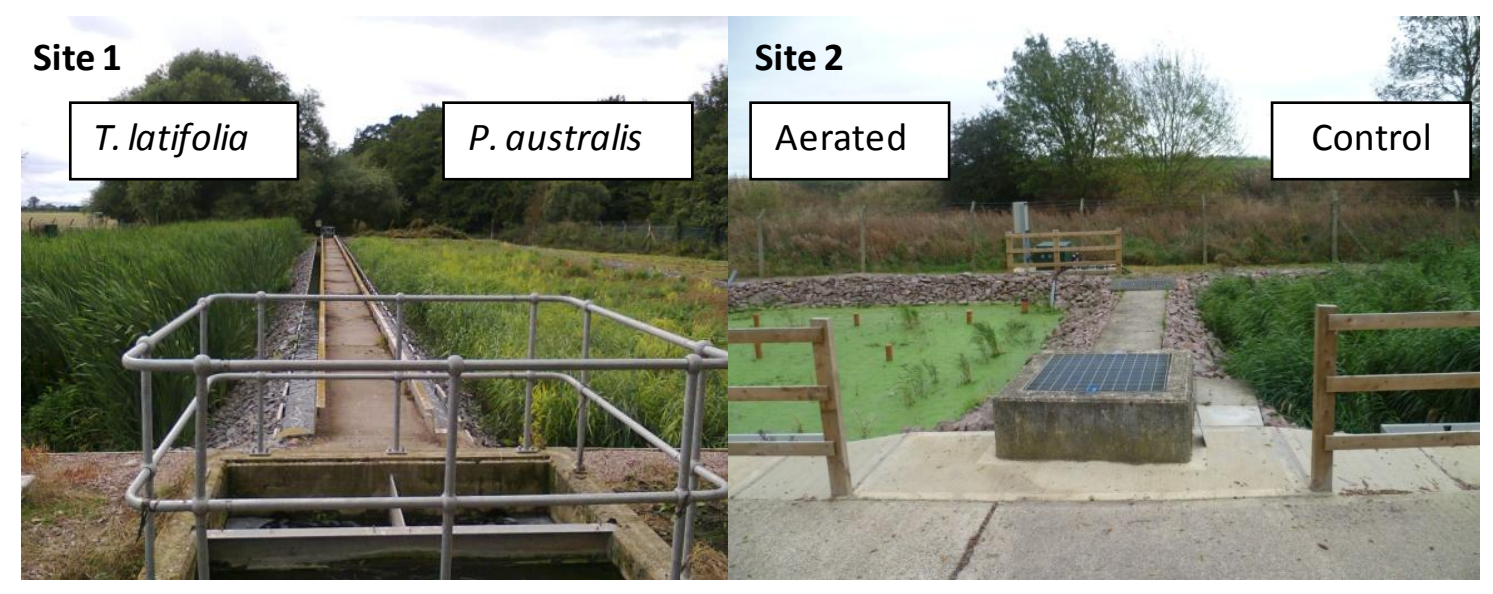

Figure 3 Full scale (Site 1) aerated beds planted with Typha latifolia (left) and Phragmites australis (right) 5 months after planting. Full scale (Site 2) aerated (left) and non-aerated control (right) 12 months after planting with P. australis.

For determination of plant abundance, each full scale bed was divided into 9 sections and the total number of plants counted. For determining the percentage of yellowing plants, the proportion of yellow reeds within the sample section was counted and related to the total number of plants. A single plant was excavated from the middle of each bed (October, 2013) by gently easing a fork to loosen the root ball and a shovel to ease it out then taken to the lab and treated as for the pilot 
studies. Plants were excavated at the end of their first growing season and third growing season in Sites 1 and 2, respectively.

\subsection{Data analysis}

The data was tested for normality before analyzing for significance on a case by case basis with the D’Agostino and Pearson omnibus normality test. As all attempts to transform the non-normal data (by squaring, lognormal, and antilog equations) were unsuccessful, non-normal data was analysed using non-parametric tools. All statistical tests were run using GraphpadPrism.6 (2014) at the 0.05 level of significance.

Differences in plant growth measured as height $(\mathrm{cm})$ between plant species and treatments (aeration intensities) was normally distributed and thus tested with a one way, repeated measures analysis of variance (ANOVA) followed by Dunnett's test to compare against each species control.

For growth rate comparisons, these were calculated as the difference in height $(\Delta \mathrm{h})$ divided by the time interval between measurements $(\Delta \mathrm{t})$. This data was nonnormal and thus analysed with a Kruskal-Wallis test.

Analysis of aboveground, roots and rhizome biomass, and micro and macro nutrients content in the pilot and full-scale systems was performed with the nonparametric Kruskal-Wallis test and, where differences were found, the post test Dunn's was used to identify these. 


\section{$3 \quad$ Results and Discussion}

\subsection{Growth}

\subsubsection{Comparison in pilot studies}

The relative growth rate in terms of height for both species was slow during the first month before a greater difference between species and the control became apparent, 33 days after planting (Figure 4). In terms of overall growth, T. latifolia grew much taller than P. australis with a maximum height observed in the control of $1380 \mathrm{~mm}$ compared to $635 \mathrm{~mm}$ seen in the P. australis control. Plant growth was reduced in all trials and when normalised against the control revealed greater absolute difference in the case of T. latifolia compared to P. australis (Figure 4). To illustrate, the median decrease in height compared to the control at the end of the growth phase was $380 \pm 24 \mathrm{~mm}$ and $580 \pm 195 \mathrm{~mm}$ in the case of the high and low aerated T. latifolia compared to $240 \pm 11 \mathrm{~mm}$ and $130 \pm 95 \mathrm{~mm}$ respectively in the case of $P$. australis. The reduction in height equated to $35-53 \%$ and $15-29 \%$ for the T. latifolia and P. australis respectively indicating that despite lower overall height, the height of $P$. australis was less affected by the presence of the aeration than T. latifolia.

Significance testing of the average relative growth rates reported significant differences of both the low and high aeration cases in comparison to the control for both species (Friedman, matched-pairs signed rank test; Friedman statistic 13.29 for P.australis and for T. latifolia $26.14, \mathrm{P}<0.0001$ ). Further analysis of the impact of aeration intensity on the overall relative growth rates (as height) compared to the control revealed no significant difference between the median values of the low 
and high aeration for P.australis (Wilcoxon matched-pairs signed rank test, $\mathrm{W}=-27$, $\mathrm{P}=0.4263$ ). However, a significant difference was recorded between the high and low aeration for T.latifolia (Wilcoxon matched-pairs signed rank test, $W=103$, $\mathrm{P}=0.0002$ ). The results are in contrast to reported observational evidence that has suggested less impact when using T.latifolia.

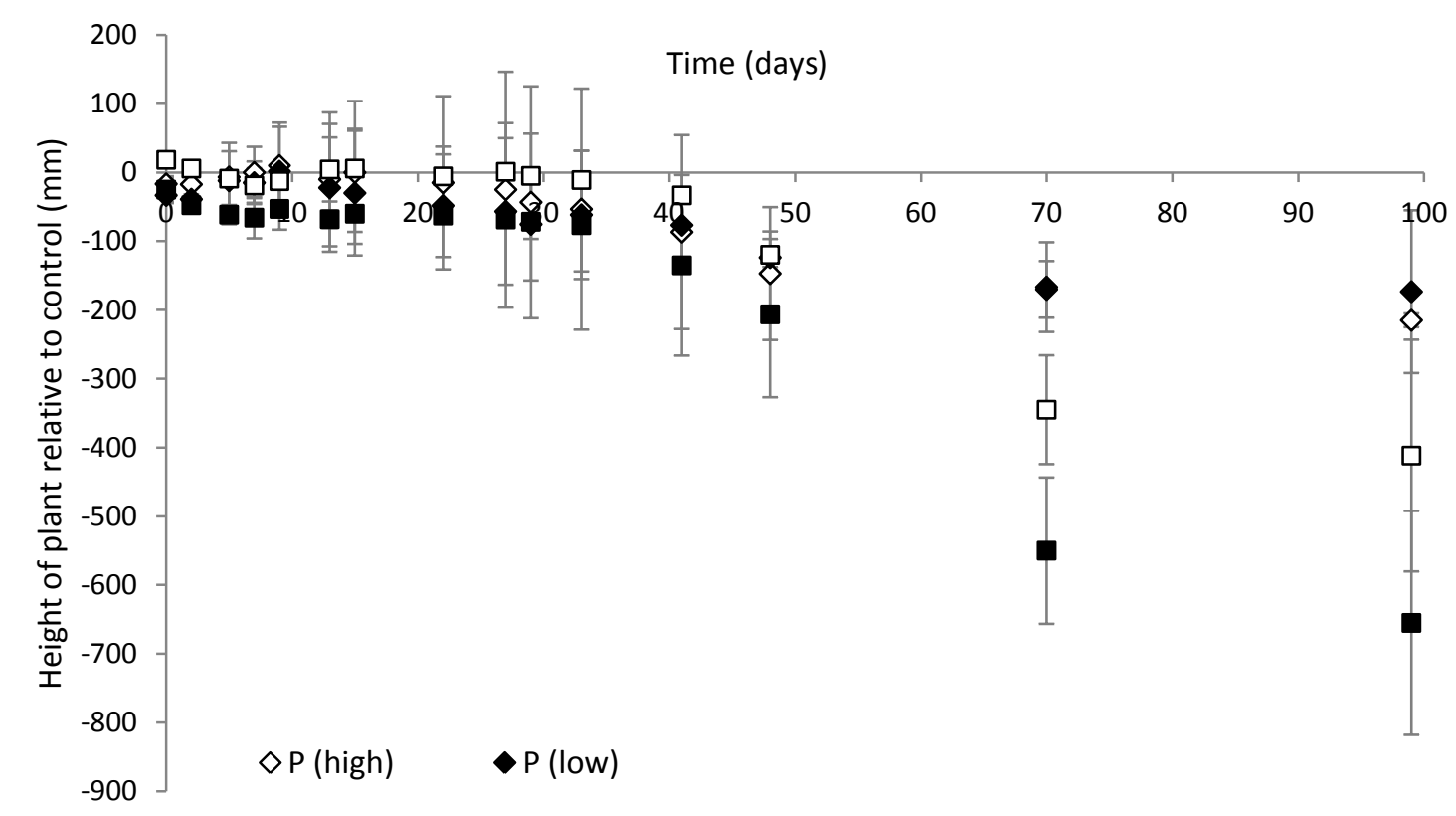

Figure 4 Relative height of aerated systems plants compared to their respective non-aerated controls over 100 days of study $(\mathrm{P}=P$. australis; $\mathrm{T}=$ T. latifolia $)$. Bars represent standard deviation.

The impact of aeration on the above ground growth occurred predominately in different features for the two species (Figure 5a). In the case of P. australis, greater impact was seen in the number of stems and leaves. In comparison, the predominant impact for T. latifolia was observed in terms of the stem diameter and the length of leaves, with no impact on leaf width in either species. For example, at the end of the growing phase, aeration reduced the number of stems 
compared to the control by $18-19$ stems and by 12 leaves in the case $P$. australis (Figure 5a) whereas the greatest absolute difference was observed in the reduction in leaf length of T. latifolia was $85-93 \mathrm{~mm}$. Statistical testing, however, was only able to find significant differences for leaf length for T. latifolia. This is potentially due to the high variability of the individual plants within each replicate, which resulted in large spread of values within one dataset. Yellowing of the leaves was observed in all cases and more predominantly in the case of the aerated beds compared to their respective controls. In addition, slight yellowing in the control beds was more pronounced in P. australis than T. latifolia.

a)

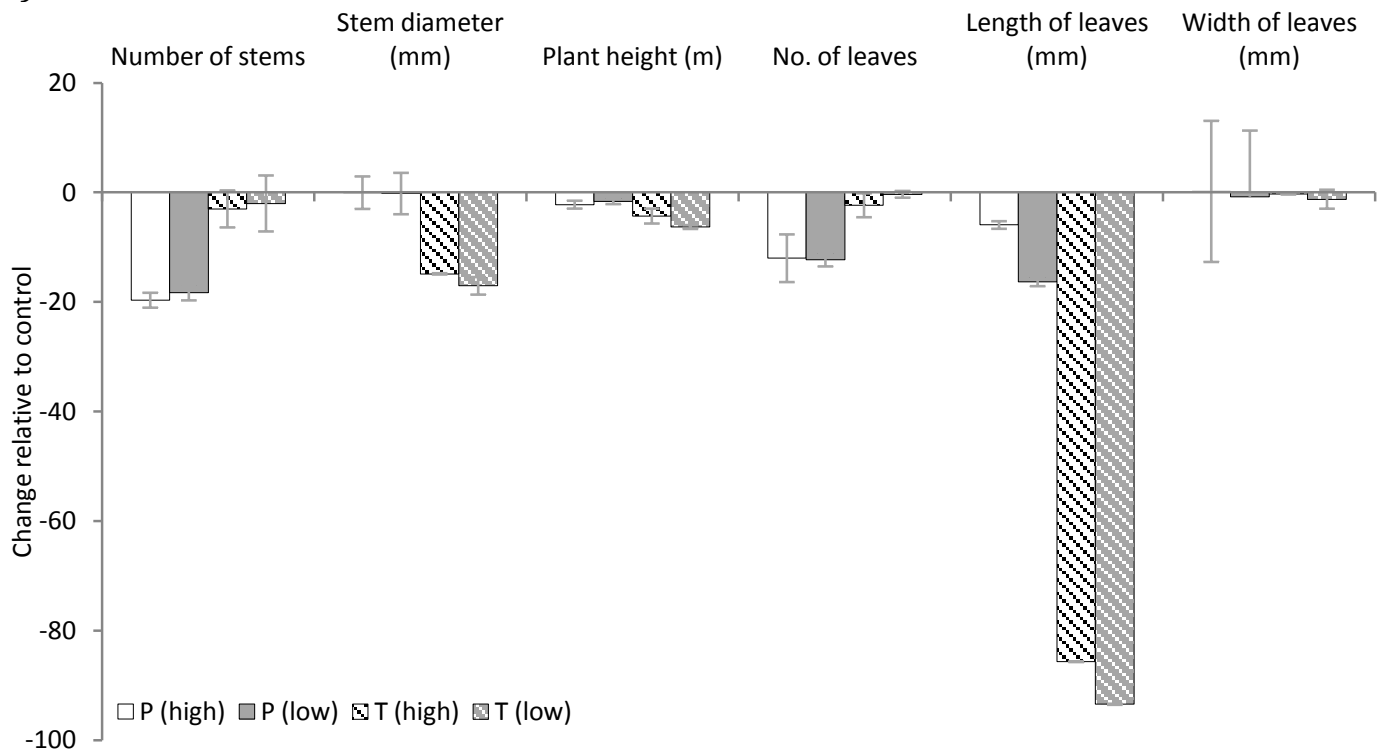




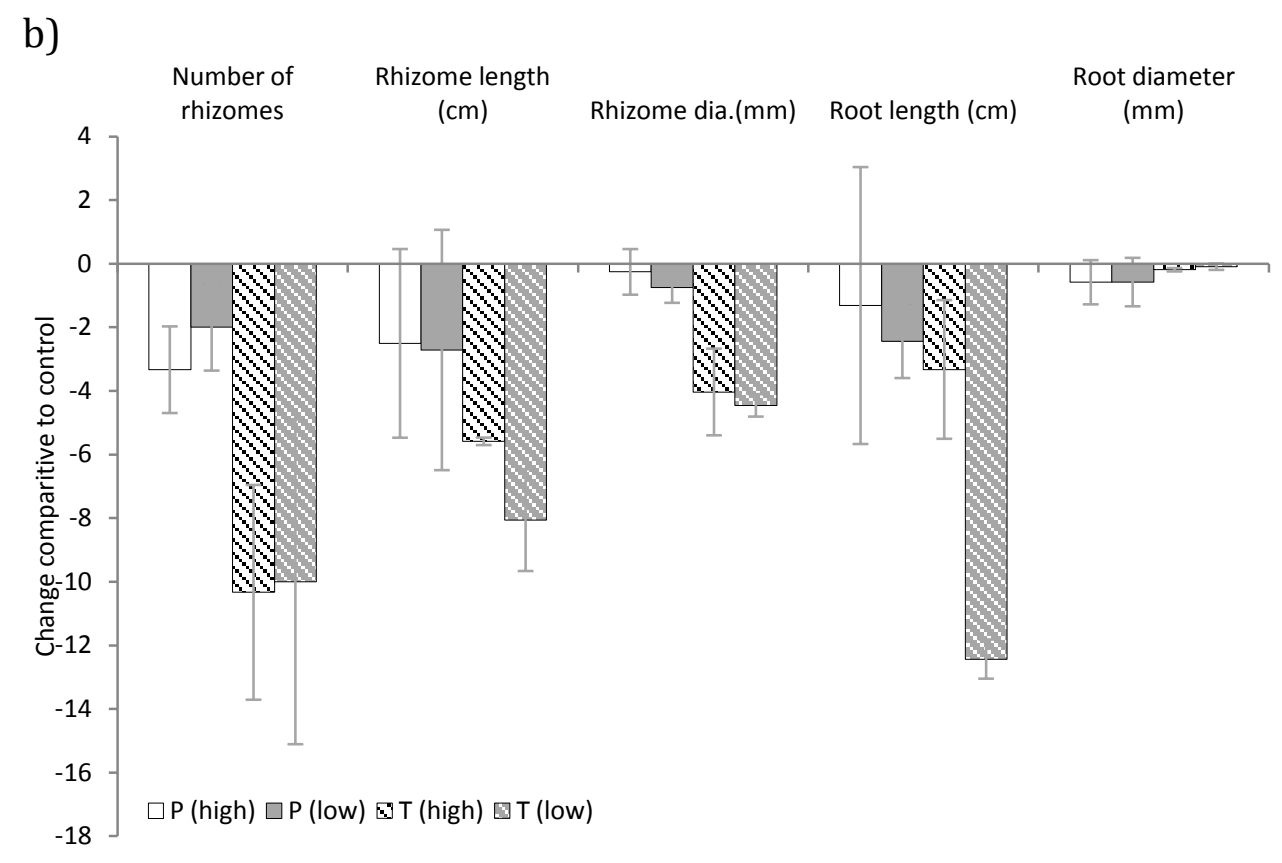

Figure 5 Difference in above ground biomass characteristics after 4 months (a), and difference in below ground biomass characteristics after 4 months relative to control $(\mathrm{b}) .(\mathrm{P}=$ P. australis; $\mathrm{T}=$ T. latifolia $)$. Bars represent standard deviation.

The below-ground measurements (Figure 5b) indicate differences in growth between both species and between aerated and non-aerated systems, although the intensity of aeration does not appear substantial. The rhizome number, length and diameter and the root length in the aerated T. latifolia trials were considerably reduced compared to the control. The number of rhizomes observed in P. australis was also smaller than the control, although to a lesser extent than T. latifolia. For example, the number of rhizomes was reduced by an average of 10 in both the high $( \pm 3)$ and low $( \pm 5)$ systems in T. latifolia, compared to $2 \pm 1$ (low) and $3 \pm 1$ (high) in $P$. australis. On first appearance, in the case of $P$. australis, the rhizome length and diameter and the root length is also reduced compared to the control but the large 
standard deviation recorded in these measurements does not allow any level of certainty. The root diameter does not seem to have been affected by the presence or intensity of aeration in either species and little effect is observed in the rhizome diameter of $P$. australis. When the standard deviations are taken into account no below ground growth parameter appears to have been affected more than another.

Visual observation of $P$. australis showed a clear difference in the size of the above ground biomass and a denser root structure with deeper reaching roots and increased number fine roots in the control (Figure 6). The T. latifolia control also displayed deep reaching roots with a couple of roots reaching the bottom of the water butt (0.6 m deep). Investigation of root integrity revealed no discernible difference in the nature of the roots between aerated and non-aerated samples. The reduced root intensity and size is indicative of stress derived growth inhibition due to root disturbance as seen in many terrestrial plants exposed to waves (Coops and Van der Velde, 1996). However, the lack of difference between aeration intensity suggests that aeration level is not a factor and that the minimum aeration levels required in aerated wetlands will exceed any potential threshold level. 
a)

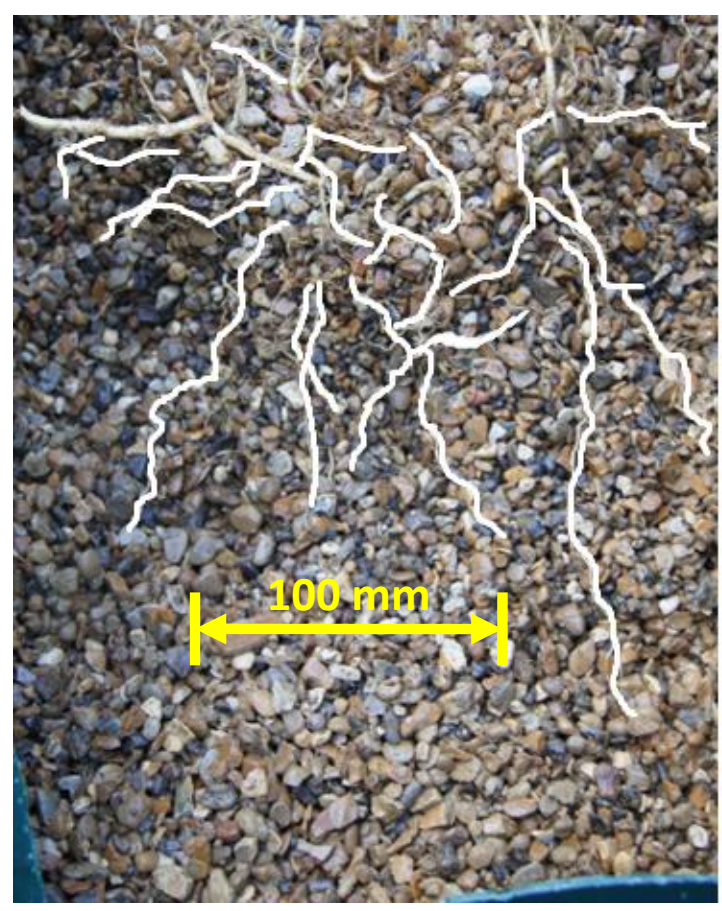

b)

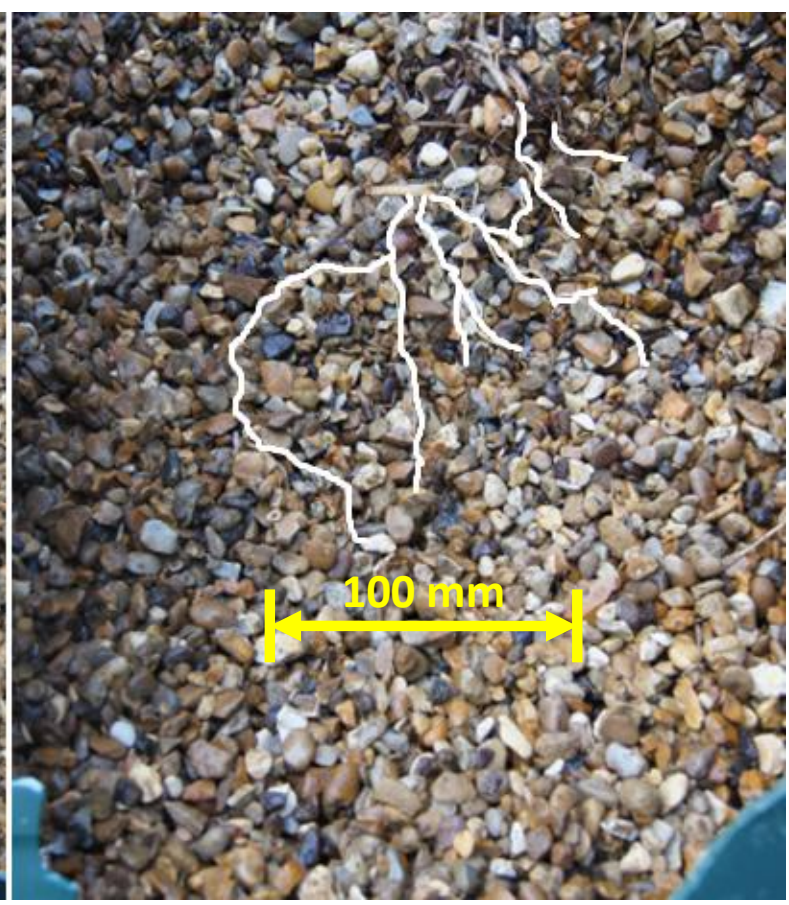

Figure 6 Example of root systems in-situ (enhanced): (a) P. australis control and (b) P. australis high aeration.

\subsubsection{Comparison on full scale beds}

Both species grew well at the inlet of the beds of Site 1 (Figure 3) in their first growing season and were largely green, upright and healthy. T. latifolia averaged a height of $2.2 \mathrm{~m} \pm 0.4 \mathrm{~m}$, compared to the P. australis which averaged $1.4 \pm 0.3 \mathrm{~m}$, giving a $P$. australis to $T$. latifolia height ratio of $1: 1.57$. The height ratio was similar in the pilot studies at 1:1.55 indicating commonality between the different scales of systems investigated. The plants gradually thinned in density, were shorter and showed signs of yellowing towards the outlet of both beds and weeds had begun to take over. The effect was much more pronounced in the P. australis bed with approximately $40 \%$ of the $P$. australis plants displaying significant yellowing as 
close as $0.3 \mathrm{~m}$ from the inlet and approximately half of the was bed taken over with weeds. In comparison, signs of stress began 3-4 m from the inlet in the T. latifolia bed, yellowing was apparent in approximately $20 \%$ of the plants and weeds took over approximately $25 \%$ of the bed. The P. australis taken for analysis from Site 1 displayed slight yellowing of the leaves. The T. latifolia also displayed slight yellowing on the outer leaves but to a visually different degree than the P. australis. T. latifolia displayed thick $(1.3 \pm 0.6 \mathrm{~cm})$, shallow, long rhizomes $(8.1 \pm 3.2 \mathrm{~cm})$ compared to the root system of $P$. australis that recorded an average of $0.6 \pm 0.3 \mathrm{~cm}$ - half the diameter found in T. latifolia; a comparatively more dense root network, with a greater number of fine roots. Observational differences in above ground growth in T. latifolia and P. australis (Site 1) indicate T. latifolia was able to establish quickly in the aerated site and out-compete the weeds more so than $P$. australis.

Site 2 allowed the comparison of the growth of $P$. australis at full scale with and without aeration. At the time of writing, the plants were coming to the end of their third growing season. This site in particular demonstrated a stark contrast between plant growth and establishment in an aerated vs. a non-aerated control (Figure 3). The control bed displayed excellent above ground growth, covering 100 $\%$ of the bed and averaging a height of $1.6 \mathrm{~m} \pm 0.3 \mathrm{~m}$ compared to a coverage of approximately $20 \%$ of the bed and an average height of $1.1 \mathrm{~m} \pm 0.5 \mathrm{~m}$. The control to aerated height ratio was $1: 1.45$, similar to the pilot which recorded 1:1.41 for the P. australis. 
A visually apparent difference was also seen between the below ground growth of P. australis in the aerated bed compared to the control (Figure 7), similar to in situ observations for this plant species at pilot scale (Figure 6). The quantitative differences were also similar to those seen in the pilot, in that the control plants were comparatively larger than in the aerated bed, illustrated by $31 \%$ taller plants in the control bed compared to $15-29 \%$ in the pilot and $66 \%$ more stems, comparable to $63-67 \%$ measured in the pilot. The leaf number indicted $73 \%$ more leaves on the control plants, more than the 37-38\% increase observed in the pilot, most likely related to the height of the stems being taller in the full scale bed after 3 growing seasons compared to the shorter stems in pilot study after only one growing season.

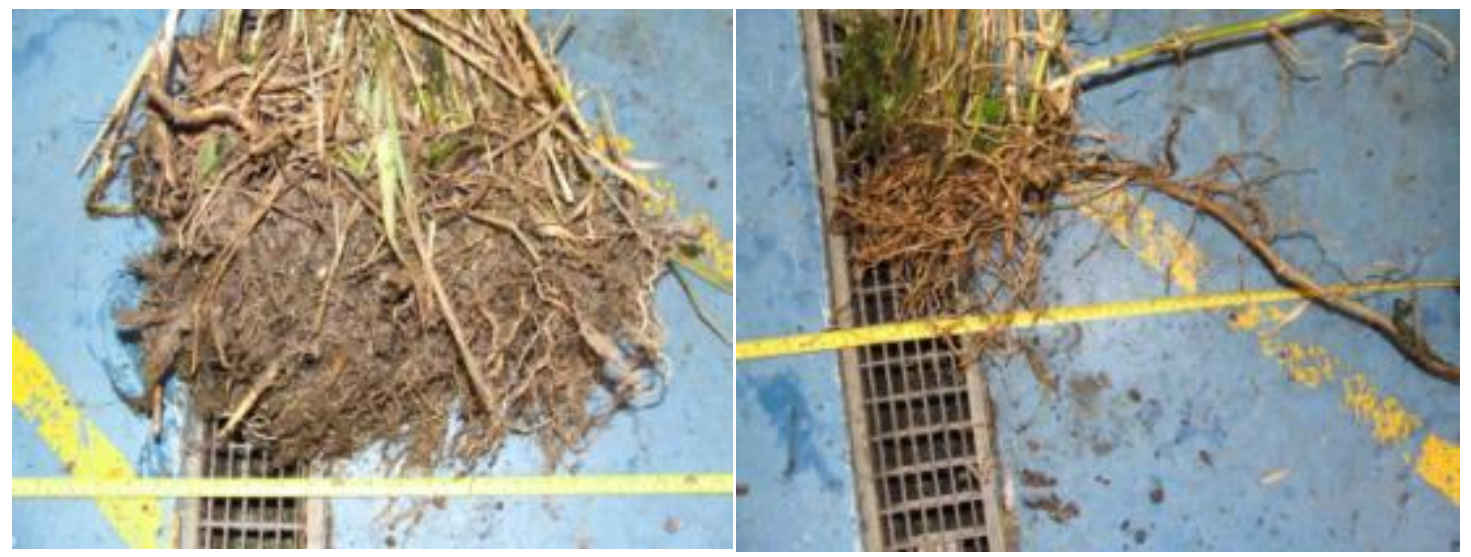

Figure 7 Below ground growth in a full scale aerated and non-aerated bed in Site 2

(a) control, (b) aerated.

\subsection{Biomass allocation}

Compared to their respective controls, there was a statistically significant decrease in plant biomass (i.e., g/plant less than the control) in $T$. latifolia for aboveground 
biomass, roots and rhizomes. In contrast, no statistical difference was found for $P$. australis. The effect of aeration intensities did not appear to affect the overall distribution of the biomass between above ground, roots and rhizomes (Figure 8).

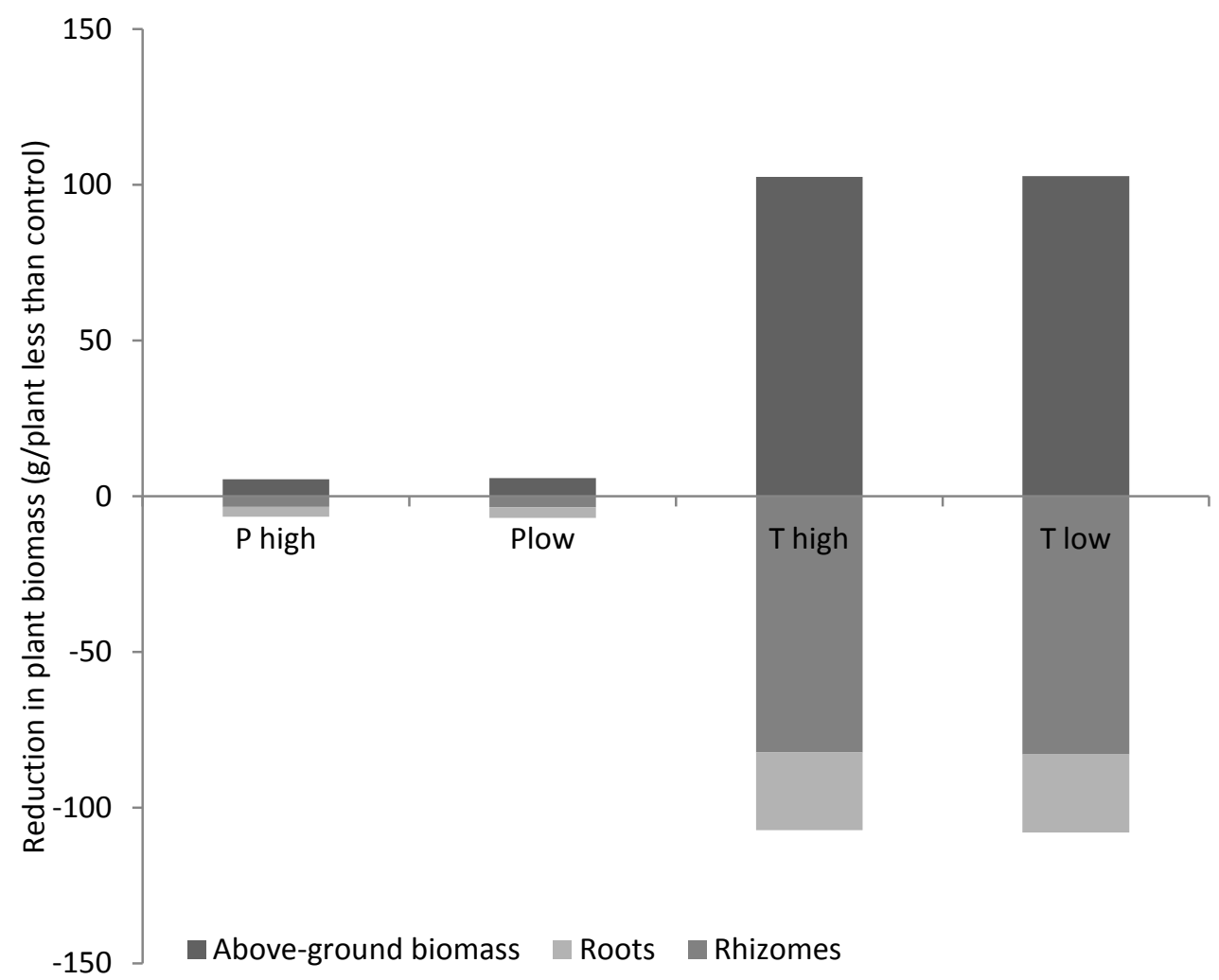

Figure 8 Reduction in plant biomass (g/plant compared to control). Negative numbers indicate below ground biomass $(\mathrm{P}=$ P. australis; $\mathrm{T}=$ T. latifolia $)$.

The ratio of below ground to above ground biomass (BGB:AGB) in the P. australis was 1:1.3-1.7 for all test conditions; comparable to reported literature values of 1.3 for standard HSSF conditions (Tanner, 1996) and 1.4-1.8 for various intensified CW systems (Nivala, 2012). The aerated tests recorded a mean of $29 \%$ of the below ground biomass allocated to the roots and $45 \%$ in the control; higher than previously reported values of $29 \%$ under non-aerated conditions (Tanner, 1996), suggesting more effort was put into rhizome growth in the aerated bed compared 
to the roots in the control. In all T. latifolia test conditions the ratio of BGB:AGB biomass was 1.3 , comparable to the $P$. australis. Allocation of biomass was similar for above ground biomass, roots and rhizomes in both the aerated tests and the non-aerated tests with $39-43 \%, 12-13 \%$ and $42-48 \%$ respectively, indicating the presence of aeration did not affect biomass distribution. Of the below ground biomass, $21 \%$ was attributed to the roots in the aerated condition and $23 \%$ in the control. This was less than observed in P. australis and there was less difference between the aerated and control.

In terms of plant size and biomass, the presence of aeration appeared to be detrimental to the growth of both species in the first growing season and to a greater degree in the $T$. latifolia compared to the $P$. australis (Table A, supplementary information). The data suggest aeration is affecting the growth of each species by different mechanisms as the most apparent differences were seen in terms of a reduction of the length of the leaves, stem diameter and number of rhizomes in T. latifolia compared to a reduction in the number of stems, the stem diameter and the number of leaves in P. australis.

\subsection{Macro and micro nutrients/trace minerals}

Macro and micro nutrient concentrations in the above ground biomass, rhizomes and roots revealed no consistent discernible differences between the non-aerated and aerated plants (Table B, supplementary information). In most cases, the concentrations observed in the control plants were within the same range as the plants exposed to low and high levels of aeration or were in between the two. 
Accordingly, no direct causal link could be identified between the observed growth differences due to aeration and changes in nutrient levels. To illustrate, in the case of copper in P. australis, the above ground biomass contained a median level of $11.3 \mu \mathrm{gCu} / \mathrm{g}$ in the non-aerated bed compared to $13.9 \mu \mathrm{gCu} / \mathrm{g}$ in the aerated bed with the high level of aeration. Across all nutrients, similarity between the nonaerated and aerated samples was more apparent in the case of $P$. australis, with indicative differences (defined as the ranges not substantially overlapping) only identified in relation to calcium levels in the roots and rhizomes (reduced from control), manganese levels in the roots and above ground biomass (reduced from the control) and an increase in sodium in the above ground biomass. In contrast, indicative differences were observed with $T$. latifolia in relation to nitrogen, magnesium, calcium, zinc and copper in the above ground biomass and manganese in the roots and rhizomes. The reported levels in the current study are within the ranges seen previously for reeds grown in a range of water types including municipal sewage (Nivala et al, 2012; Moises, 2012), salt marshes (Windham et al, 2003), dairy wastewater (Tanner, 1996), coal ash basin (Babcock et al, 1983) but lower than those from plants used for treatment of sewage sludge (Obarska et al, 2002).

Both species have been reported to function on an excluder strategy with regard to metal translocation (Windham et al, 2003) such that the majority of metals can be expected to reside in the roots in order to protect photosynthetic function in the leaves (MacFarlane and Burchett, 2000). The data from the current trial broadly supports this, with the exception of nickel that was generally more evenly 
distributed between the above ground biomass and the roots. To illustrate, above ground biomass:root ratio for nickel ranged between 1.03 and 1.54 indicating higher levels in the above ground biomass in all cases. In contrast, the equivalent ratio for copper ranged between 0.43 for the $P$. australis non-aerated to 0.57 for the T. latifolia aerated with an equivalent range for zinc of 0.44-1.0. Similar measurements, but based on the ratio of shoots to roots indicates much greater partitioning with maximum levels of $\sim 0.15$ when examining P. australis grown in salt marshes (Windham et al, 2003) and 0.21 in lake water (Schierop and Larsen, 1981), whereas shoot to rhizome ratios of 1:1 for copper and zinc have previously been reported for T. latifolia treating coal ash basin wastewater (Babcock et al, 1983). This compares to ratios for T. latifolia in the current study of 0.7 and 1.9 for copper and 0.23 and 0.9 for zinc for the non-aerated and aerated plants respectively. Overall, analysis of the data revealed changes in partitioning between the plants grown in non-aerated and aerated conditions, and between species, but not in a consistent or statistically significant manner to discern an identifiable probable cause.

Previous discussions on the impact of aeration on nutrient uptake have focused on iron deficiency as the potential cause of the stunted growth and chlorosis of leaves in aerated CWs (Weedon, 2014). This is consistent with the aerobic environments and circumneutral $\mathrm{pH}$ leading to the majority of the iron existing in a precipitated iron hydroxide form such that truly dissolved levels in the water are likely to range between 0.1 and $0.5 \mu \mathrm{gFe} / \mathrm{L}$ based on iron equilibrium chemistry. In the current trials, average iron levels in the above ground biomass in the case of $P$. australis 
were $0.5 \mathrm{mgFe} / \mathrm{gDM}$ (range: $0.1-1.2$ ) in the control compared to $0.2 \mathrm{mg} / \mathrm{gDM}$ (range: $0.1-0.3$ ) for the low aeration level and $0.4 \mathrm{mgFe} / \mathrm{gDM}$ (range 0.2-0.5) in the case of the high aeration level (Figure 10a). Similar patterns were observed in terms of the roots and rhizomes, offering some support for the proposed mechanism. In contrast, in the full scale site with the test and control beds, iron levels were higher in the above ground biomass in the aerated bed at 0.6 $\mathrm{mgFe} / \mathrm{gDM}$ compared to $0.2 \mathrm{mgFe} / \mathrm{gDM}$ in the control bed. This compares to 0.45 $\pm 0.058 \mathrm{mgFe} / \mathrm{gDM}$ for AGB from a non-aerated wetland treating secondary effluent at a municipal sewage works (Moises, 2012) suggesting no deficiency in the above ground biomass, where the iron is utilised as part of the photosynthetic function. The reverse was observed in the rhizome and roots where substantially more iron was present in the plants in the control bed at 4.5 and $6.7 \mathrm{mgFe} / \mathrm{gDM}$ in the roots and rhizome compared to 1.0 and $0.6 \mathrm{mgFe} / \mathrm{gDM}$, respectively, in the plants grown in the aerated bed. In the control beds, as in natural wetland systems, the Fe precipitates on the aerobic roots forming an iron plaque, as this is the most aerobic environment. In the aerated systesm, precipitation can take place throughout the media, potentially explaining this difference. Aggregate iron content in the roots from plants used in a variety of different wetland configurations (including aerated beds) have been reported at 0.84-3.5 mgFe/gDM (Nivala et al, 2012). Further, in a study concerning the impact of elevated iron levels in water, mean root iron contents of $5.5 \pm 0.8 \mathrm{mgFe} / \mathrm{gDM}$ were observed once the water contained $0.5 \mathrm{mg} / \mathrm{L}$ of iron with a range of $0.2-2.2 \mathrm{mgFe} / \mathrm{gDM}$ when iron concentrations were $0.1 \mathrm{mgFe} / \mathrm{L}$ (Batty and Younger, 2003). Iron levels during the 
current trials were around 0.1-0.5 mgFe/L indicating greater iron accumulation in the current trial than previously reported.

a)

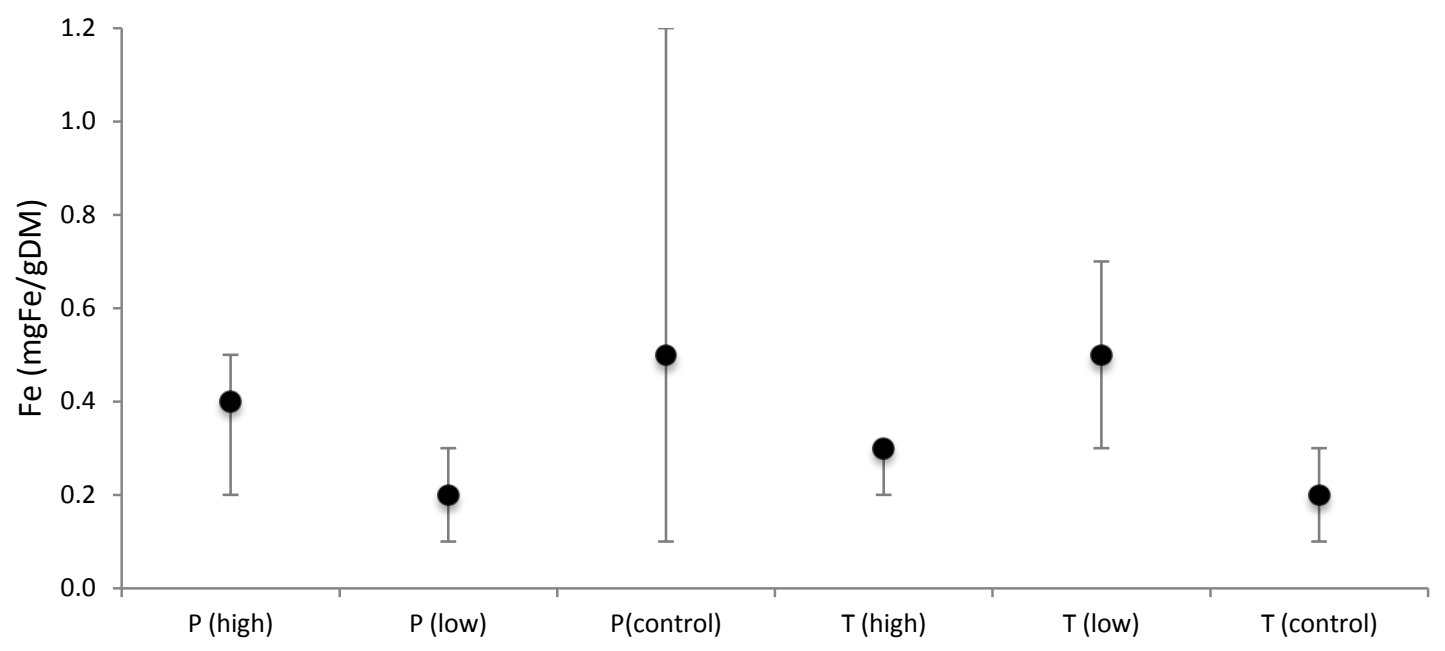

b)

Plant species and aeration level

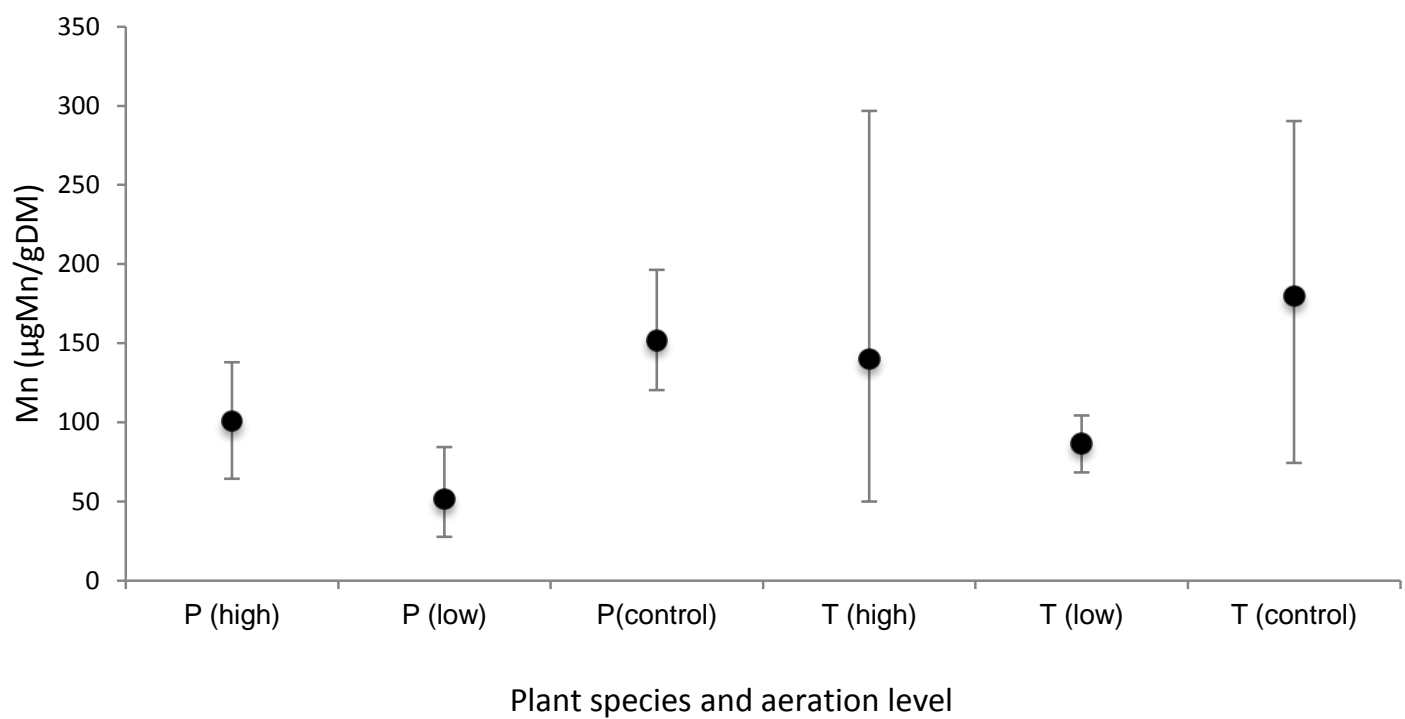

Figure 10 Iron (a) and manganese (b) concentrations in the above ground biomass of plants from the pilot study at the end of the growing season $(\mathrm{P}=$ P. australis; $\mathrm{T}=$ T. latifolia). Bars represent standard deviation. 
Manganese was also reduced in the above ground biomass for both the pilot trials (Figure 10b) and the full scale sites sampled in the aerated compared to the nonaerated beds. To illustrate, in the aerated beds planted with $P$. australis, manganese levels for the AGB, ranged between 27.7-138 $\mu \mathrm{gMn} / \mathrm{gDM}$ compared to 120-196 $\mu \mathrm{gMn} / \mathrm{gDM}$ in the case of the non-aerated samples. Required nutrient concentrations for healthy plant growth are very species specific but a general estimate of the required levels of Fe and Mn are $0.1 \mathrm{mgFe} / \mathrm{gDM}$ and $50 \mu \mathrm{gMn} / \mathrm{gDM}$ respectively (Barker and Pilbeam, 2007) indicating that the aeration was more likely to have influenced available manganese levels than iron. Manganese, like iron is essential for chlorophyll production and its deficiency is often confused with, and occurs concurrently with iron deficiency, both displaying similar symptoms of interveinal chlorosis of the leaves. $\mathrm{Mn}^{2+}$ is the primary form in which Mn is absorbed by plants and is most available at pH 5-6.5 (Hong et al, 2010). Conditions that restrict availability are similar to those for iron based around neutral or slightly alkaline $\mathrm{pH}$, aerobic conditions and the presence of relatively higher levels of iron, copper or zinc, consistent with aspects of the environments found within the aerated beds.

\subsection{Implications for aerated wetland design}

The results indicate both plant species are negatively affected by aeration, albeit to different extents. The visual appearance of the plants is one of the key positive attributes of the technology, with both designers and users preferring wetland beds that are green and lush during the growing season to yellow and generally unhealthy looking plants. There is an additional perception concern that if the 
plants look unwell, the wetland could be under performing in terms of its treatment ability.

T. latifolia was shown to be more impacted by aeration than P. australis when assessing it against their relative controls; however, because of the faster growth rate of $T$. latifolia, the visual impact was significantly reduced, with improved plant coverage observed in the full scale sites. As such, T. latifolia presents the opportunity to provide fast, initial cover of the wetland bed thus delivering insulation, shading and aesthetics benefits in the first year of operation. However, the increased rate of biomass generation (Figure 8; Table A) when compared against $P$. australis could have an impact on leaf litter accumulation and, as a result, what is considered the average asset life of a conventional tertiary HSSF bed (Knowles et al, 2011). To prevent a potential negative impact on asset life, annual harvesting of the above ground biomass could be implemented. This, however, has a financial and carbon cost that will be site specific as it is highly dependent on the end use or fate of the harvested biomass (e.g., composting, digestion, incineration, or landfill disposal). With both plants negatively impacted by aeration, the choice between the two should be based on the key priorities at the specific site.

\subsection{Conclusions}

Overall, the results confirm reports of the negative impacts of aeration on plant growth in terms of visual differences in stunted growth and yellowing of leaves. The effects appear to be species specific, with aeration impacting more in terms of fresh growth in the case of $P$. australis (number of stems and leaves) and more with respect to the size of stems and leaves in the case of T. latifolia. Whilst on an 
individual plant basis, T. latifolia was more strongly influenced by aeration than $P$. australis compared to their respective controls, the impact on the overall growth was less significant. This is congruent with T. latifolia's faster growing rate. Consequently, T. latifolia is recommended where rapid plant cover is required in an aerated wetland. Where lower levels of above ground biomass is preferred (e.g., to reduce leaf litter accumulation in the absence of harvesting practices), $P$. australis would be preferred.

Micro and macro nutrient content analyses and visual observations of the plants from both the controlled pilot trials and full scale beds were inconclusive in providing a definitive mechanism for observed retarded growth. However, a potential synergistic impact is suggested in relation to both iron and manganese. This is the first study to employ a systematic, scientific approach to try to elucidate why in some aerated systems macrophytes struggle to establish and/or shown signs of stress.

\section{Acknowledgments}

The authors would like to express their gratitude for the financial and resource support of the work from Severn Trent Water Limited and to the EPSRC for their allocation of funding and support of the project (grant EP/I501347/1). The authors also gratefully appreciate the informal discussions held on potential causes for aerated wetlands reeds poor establishment held in early 2012 with S. Wallace, J Nivala, Y. Comeau, O. Stein, D. Rosseau, S. Tyrell, S. Gowing, and ARM Ltd. 


\section{$5.7 \quad$ References}

Babcock M., Evans D., Alberts J. (1983) Comparative uptake and translocation of trace elements from coal ash by Typha latifolia. Science of the Total Environment 28(1-3):203-214

Barker A., Pilbeam D. (2007). Handbook of plant nutrition. Taylor and Francis. New York

Batty L., Younger P (2003) Effects of External Iron Concentration upon Seedling Growth and Uptake of Fe and Phosphate by the Common Reed, Phragmites australis (Cav.) Trin ex. Steudel. Annals of Botany 92(6):801-806

Brix H. (1997) Do macrophytes play a role in constructed treatment wetlands? Water Science and Technology 35(5):11-17

Butterworth E., Dotro G., Jones M., Richard, A., Onunkwo P., Narroway Y., Jefferson B. (2013) Effect of artificial aeration on tertiary nitrification in a full-scale subsurface horizontal flow constructed wetland. Ecological Engineering 54:236244

Coops H., Van der Velde (1996) Effects of waves on helophyte stands: mechanical characteristics of stems of Phragmites australis and Scirpus lacustris. Aquatic Botany 53(3-4):175-185 
Hong E., Ketterings Q., McBride M. (2010) Agronomy Fact Sheet 49: Manganese. Available online at:

http://nmsp.cals.cornell.edu/publications/factsheets/factsheet49.pdf [Accessed $3 / 3 / 2014]$

Jesperson D., Sorrell B., Brix H. (1998) Growth and root oxygen release by Typha latifolia and its effects on sediment methanogenesis. Aquatic Botany 61(3):165180

Kadlec R., Wallace S. (2009) Treatment Wetlands (2nd edn). Taylor \& Francis Group:Florida

Knowles, P., Dotro, G., Nivala, J., García, J., 2011. Clogging in subsurface-flow treatment wetlands: occurrence and contributing factors. Ecological Engineering 37 (2): 99-112.

Langergraber G. (2005) The role of plant uptake on the removal of organic matter and nutrients in subsurface flow constructed wetlands: a simulation study. Water Science and Technology 51(9):213-233

MacFarlane G., Burchett M. (2000) Cellular distribution of copper, lead and zinc in the grey mangrove Avicennia marina (Forsk.) Vierh. Aquatic Botany 68(1):45-59 
Mitsch W., Gosselink J. (2000) Wetlands (3rd edn). Van Nostrand Reinhold: New York

Moises P-M. (2012) Evaluating the application of harvested reeds in anaerobic digestion. MSc Thesis: Cranfield University

Nivala J. (2012) Effect of design on treatment performance, plant nutrition and clogging in subsurface flow treatment wetlands. PhD Thesis: Aarhus University

Obarska-Pempkowiak H., Tuszynska A., Sobocinski Z. (2002) Polish experience with sewage sludge dewatering in reed systems. Water Science and Technology 48(5):111-117

Ouellet-Plamondon C., Chazarenc F., Comeau Y., Brisson J. (2006) Artificial aeration to increase pollutant removal efficiency of constructed wetlands in cold climate. Ecological Engineering 27(3):258-264

Schierup H., Larsen V. (1981) Macrophyte cycling of zinc, copper, lead and calcium in the littoral zone of a polluted and non-polluted lake I. Availability, uptake and translocation of heavy metals in Phragmites australis (Cav.) Trin. Aquatic Botany 11(3):197-210

Stottmeister U., Wießner A., Kuschk P., Kappelmeyer U., Kästner M., Bederski O., Müller R., Moormann H. (2003) Effects of plants and microorganisms in 
constructed wetlands for wastewater treatment. Biological Advances 22(1-2):93117

Tanner C. (1996) Plants for constructed wetland treatment systems- A comparison of the growth and nutrient uptake of eight emergent species. Ecological Engineering 7(1):59-83

Weedon C. (2014) Yellow Phragmites: Significance, Cause, and Remedies. Sustainable sanitation practice 18:37-42

Windham L., Weis J., Weis P. (2003) Uptake and distribution of metals in two dominant salt marsh macrophytes, Spartina alterniflora (cordgrass) and Phragmites australis (common reed). Estuarine, Coastal and Shelf Science 56(1):63-72

Zhang L., Liu Y., Shen Y., Liu H., Xiong Y. (2010) Effect of limited artificial aeration on constructed wetland treatment of domestic wastewater. Desalination 250(3): $915-920$ 


\section{Supplementary information}

Table A Biomass growth at the end of the study in each of the treatments

\begin{tabular}{|c|c|c|c|c|c|c|c|c|c|c|c|c|}
\hline & \multicolumn{2}{|c|}{ P (high) } & \multicolumn{2}{|c|}{ P (low) } & \multicolumn{2}{|c|}{$\mathrm{P}$ (control) } & \multicolumn{2}{|c|}{$\mathrm{T}$ (high) } & \multicolumn{2}{|c|}{$\mathrm{T}$ (low) } & \multicolumn{2}{|c|}{$\mathrm{T}$ (control) } \\
\hline & Mean & Min-Max & Mean & Min-Max & Mean & Min-Max & Mean & Min-Max & Mean & Min-Max & Mean & Min-Max \\
\hline $\begin{array}{l}\text { Above ground } \\
\text { biomass }(\mathrm{g})\end{array}$ & 1.97 & $0.56-3.4$ & 1.63 & $0.62-3.38$ & 7.39 & $3.48-14.44$ & 3.96 & $3.47-3.48$ & 3.73 & $2.18-4.54$ & 106.53 & $46.38-142.52$ \\
\hline Roots (g) & 0.75 & $0.41-1.41$ & 0.54 & $0.17-0.94$ & 3.98 & $1.8-7.53$ & 1.12 & $0.92-1.26$ & 1.06 & $0.58-1.93$ & 26.07 & $10.11-36.41$ \\
\hline Rhizomes (g) & 1.95 & $0.3-3.53$ & 1.83 & $0.71-3.41$ & 5.33 & $1.75-10.77$ & 4.30 & $3.36-5.15$ & 3.62 & $3-4.12$ & 86.59 & $39.69-119.7$ \\
\hline Total (g) & 4.67 & & 4.00 & & 16.71 & & 9.38 & & 8.42 & & 219.20 & \\
\hline
\end{tabular}


Table B Micro and macro nutrient concentrations in plant fractions from pilot and full scale studies

\begin{tabular}{|c|c|c|c|c|c|c|c|c|c|c|c|c|c|}
\hline & & \multicolumn{2}{|c|}{ P (high) } & \multicolumn{2}{|c|}{$\mathrm{P}$ (low) } & \multicolumn{2}{|c|}{$\mathrm{P}$ (control) } & \multicolumn{2}{|c|}{$\mathrm{T}$ (high) } & \multicolumn{2}{|c|}{$\mathrm{T}$ (low) } & \multicolumn{2}{|c|}{$\mathrm{T}$ (control) } \\
\hline & & Mean & Min-Max & Mean & Min-Max & Mean & Min-Max & Mean & Min-Max & Mean & Min-Max & Mean & Min-Max \\
\hline \multirow{11}{*}{$\begin{array}{l}\text { Above } \\
\text { ground } \\
\text { biomass }\end{array}$} & $\mathrm{N}(\mathrm{mg} / \mathrm{g} \mathrm{DM})$ & 22.7 & $17.1-26.0$ & 25.5 & $19.7-31.4$ & 24.5 & $21.7-26.5$ & 19.9 & $17.7-21.7$ & 20.5 & $19.5-21.9$ & 9.9 & $9.4-10.6$ \\
\hline & $\mathrm{P}(\mathrm{mg} / \mathrm{g} \mathrm{DM})$ & 2.1 & $1.9-2.3$ & 1.8 & $1.1-2.1$ & 1.9 & $1.3-2.0$ & 2.2 & $2.1-2.3$ & 1.8 & $1.6-2.2$ & 1.5 & $1.1-2.2$ \\
\hline & $\mathrm{K}(\mathrm{mg} / \mathrm{g} \mathrm{DM})$ & 15.4 & $11.1-20.5$ & 7.0 & $3.9-9.1$ & 15.4 & $11.9-18.5$ & 19.4 & $15.4-22.9$ & 8.5 & $15.7-21.4$ & 25.4 & $13.5-34.9$ \\
\hline & $\operatorname{Mg}(\mathrm{mg} / \mathrm{g} \mathrm{DM})$ & 2.2 & $1.9-2.5$ & 1.5 & $1.4-1.6$ & 2.4 & $2.2-2.7$ & 3.0 & $2.4-3.3$ & 2.2 & $6.3-11.3$ & 1.4 & $1.0-1.9$ \\
\hline & $\mathrm{Ca}(\mathrm{mg} / \mathrm{g} \mathrm{DM})$ & 5.6 & $4.0-6.6$ & 4.3 & $3.4-6.2$ & 4.2 & $3.8-4.7$ & 25.6 & $15.7-40.1$ & 17.8 & $15.7-21.4$ & 8.0 & 1.6-13.1 \\
\hline & $\mathrm{Na}$ (mg/g DM & 3.9 & $3.3-5.0$ & 2.4 & $1.0-3.6$ & 1.3 & $0.9-1.7$ & 6.6 & $5.5-7.4$ & 4.1 & $2.6-5.7$ & 2.9 & $1.0-4.7$ \\
\hline & $\mathrm{Zn}(\mu \mathrm{g} / \mathrm{g} \mathrm{DM})$ & 82.0 & $43.2-125.2$ & 47.4 & $29.4-72.0$ & 98.8 & $66.8-160.0$ & 116.4 & $60.4-177.2$ & 91.1 & $49.6-149.2$ & 26.5 & $22.6-31.4$ \\
\hline & $\mathrm{Cu}(\mu \mathrm{g} / \mathrm{g} \mathrm{DM})$ & 13.9 & $9.3-18.3$ & 10.1 & $7.1-16.2$ & 11.3 & 7.9-14.6 & 13.1 & $12.5-13.9$ & 17.4 & $11.9-22.4$ & 6.1 & $4.9-6.8$ \\
\hline & Ni ( $\mu \mathrm{g} / \mathrm{g} \mathrm{DM})$ & 18.3 & $5.0-44.4$ & 26.3 & $4.6-67.2$ & 17.7 & $4.0-42.4$ & 8.5 & $3.6-13.6$ & 7.9 & $3.7-15.6$ & 9.3 & $6.6-10.8$ \\
\hline & Mn $(\mu \mathrm{g} / \mathrm{g} D M)$ & 100.9 & $64.4-138.0$ & 51.6 & $27.7-84.4$ & 151.9 & $120.4-196.4$ & 140.0 & $50.0-296.8$ & 86.8 & $68.4-104.4$ & 179.9 & 74.4-290.4 \\
\hline & $\mathrm{Fe}(\mathrm{mg} / \mathrm{g} \mathrm{DM})$ & 0.4 & $0.2-0.5$ & 0.2 & 0.1-0.3 & 0.5 & $0.1-1.2$ & 0.3 & $0.2-0.3$ & 0.5 & $0.3-0.7$ & 0.2 & 0.1-0.3 \\
\hline \multirow[t]{11}{*}{ Rhizomes } & $\mathrm{N}(\mathrm{mg} / \mathrm{g} \mathrm{DM})$ & 20.1 & $16.7-23.5$ & 23.6 & $22.6-25.4$ & 24.9 & $22.1-30.4$ & 21.9 & $18.2-26.3$ & 26.2 & $22.9-31.7$ & 15.2 & $13.4-18.6$ \\
\hline & $\mathrm{P}(\mathrm{mg} / \mathrm{g} \mathrm{DM})$ & 1.8 & $1.7-2.0$ & 1.7 & $1.5-2.0$ & 2.3 & $2.0-2.6$ & 1.8 & $1.1-2.4$ & 1.7 & $0.7-2.3$ & 2.2 & $2.0-2.5$ \\
\hline & $\mathrm{K}(\mathrm{mg} / \mathrm{g} \mathrm{DM})$ & 7.4 & $5.3-9.6$ & 6.4 & $4.7-8.5$ & 12.4 & $7.0-15.7$ & 15.6 & 13.3-19.1 & 12.4 & $9.5-14.3$ & 16.4 & $16.0-17.5$ \\
\hline & $\mathrm{Mg}(\mathrm{mg} / \mathrm{g} \mathrm{DM})$ & 0.7 & $0.6-0.8$ & 0.8 & $0.6-1.2$ & 1.2 & $0.6-2.1$ & 1.5 & $0.9-2.1$ & 2.0 & $1.7-2.4$ & 1.3 & $1.1-1.6$ \\
\hline & $\mathrm{Ca}(\mathrm{mg} / \mathrm{g} \mathrm{DM})$ & 0.8 & $0.7-0.9$ & 1.5 & $0.8-3.1$ & 3.8 & $0.7-9.5$ & 4.2 & $0.6-8.0$ & 4.8 & $2.6-6.7$ & 2.1 & $1.4-2.4$ \\
\hline & $\mathrm{Na}$ (mg/g DM & 0.9 & $0.6-1.2$ & 2.3 & $0.9-5.0$ & 2.4 & $0.7-4.7$ & 4.5 & $1.1-8.4$ & 3.8 & $3.5-4.1$ & 2.8 & $1.6-4.2$ \\
\hline & $\mathrm{Zn}(\mu \mathrm{g} / \mathrm{g} \mathrm{DM})$ & 35.1 & $31.6-38.6$ & 45.3 & $38.3-49.6$ & 43.3 & $30.6-55.2$ & 37.6 & $25.2-61.2$ & 31.2 & $30.2-32.2$ & 34.0 & $23.1-52.0$ \\
\hline & $\mathrm{Cu}(\mu \mathrm{g} / \mathrm{g} \mathrm{DM})$ & 8.4 & $7.3-9.6$ & 12.1 & $10.1-15.5$ & 10.3 & $8.8-12.6$ & 6.8 & $5.4-8.0$ & 10.1 & $5.2-16.6$ & 8.0 & $6.5-10.6$ \\
\hline & Ni ( $\mu \mathrm{g} / \mathrm{g}$ DM) & 3.6 & $2.5-4.7$ & 5.4 & $2.7-8.1$ & 5.9 & $3.5-8.8$ & 12.6 & $1.8-20.1$ & 8.6 & $3.7-14.0$ & 9.1 & $6.4-12.2$ \\
\hline & Mn $(\mu \mathrm{g} / \mathrm{g} \mathrm{DM})$ & 27.8 & $26.8-28.8$ & 35.9 & $32.8-38.6$ & 47.2 & $20.7-72.8$ & 14.5 & $13.6-15.4$ & 24.8 & $9.1-47.2$ & 36.8 & $18.0-61.2$ \\
\hline & $\mathrm{Fe}(\mathrm{mg} / \mathrm{g} \mathrm{DM})$ & 0.3 & $0.2-0.3$ & 0.1 & $0.1-0.2$ & 0.3 & $0.1-0.5$ & 0.1 & 0.1-0.1 & 0.3 & 0.0-0.5 & 0.1 & 0.1-0.2 \\
\hline \multirow[t]{3}{*}{ Roots } & $\mathrm{N}(\mathrm{mg} / \mathrm{g} \mathrm{DM})$ & 17.3 & $13.7-20.8$ & 14.3 & - & 17.1 & $8.3-22.8$ & 12.7 & $12.4-12.9$ & 12.1 & 11.1-13.7 & 10.2 & $9.4-11.1$ \\
\hline & $\mathrm{P}(\mathrm{mg} / \mathrm{g} \mathrm{DM})$ & 0.8 & $0.7-1.0$ & 1.5 & - & 0.9 & $1.6-1.2$ & 0.9 & $0.8-1.4$ & 0.8 & $0.7-0.8$ & 1.6 & 1.6 \\
\hline & $\mathrm{K}(\mathrm{mg} / \mathrm{g} \mathrm{DM})$ & 7.3 & $3.1-11.5$ & 14.1 & - & 6.8 & $2.3-12.5$ & 13.3 & $11.2-16.0$ & 6.1 & $4.3-.2$ & 10.3 & $7.0-13.7$ \\
\hline
\end{tabular}




\begin{tabular}{|c|c|c|c|c|c|c|c|c|c|c|c|c|}
\hline & $\mathrm{Mg}(\mathrm{mg} / \mathrm{g} \mathrm{DM})$ & 1.9 & $1.8-2.1$ & $1.5-$ & 1.6 & $1.2-2.0$ & 2.0 & $1.5-2.3$ & 2.3 & $1.7-3.0$ & 1.4 & $1.2-1.6$ \\
\hline & Ca (mg/g DM) & 5.7 & $3.0-8.4$ & $2.7 \quad-$ & 9.4 & $6.0-15.0$ & 24.3 & $20.5-30.7$ & 11.1 & $7.6-12.9$ & 14.0 & 4.9-23.1 \\
\hline & $\mathrm{Na}(\mathrm{mg} / \mathrm{g} \mathrm{DM}$ & 1.4 & $1.2-1.6$ & $1.2-$ & 1.5 & $0.9-2.3$ & 6.4 & $5.0-8.8$ & 4.8 & $4.1-6.0$ & 5.0 & $1.3-8.6$ \\
\hline & $\mathrm{Zn}(\mu \mathrm{g} / \mathrm{g} \mathrm{DM})$ & 184.4 & $84.0-284.8$ & $75.6 \quad-$ & 97.1 & $72.0-130.4$ & 165.6 & $156.8-174.4$ & 127.6 & $52.8-232.8$ & 52.4 & $38.0-66.8$ \\
\hline & $\mathrm{Cu}(\mu \mathrm{g} / \mathrm{g} \mathrm{DM})$ & 26.7 & $19.8-33.6$ & $26.0 \quad-$ & 26.5 & $20.4-30.6$ & 22.9 & $21.2-25.7$ & 20.6 & $16.6-28.6$ & 12.7 & $10.3-15.1$ \\
\hline & $\mathrm{Ni}(\mu \mathrm{g} / \mathrm{g} \mathrm{DM})$ & 11.9 & $3.6-20.2$ & $13.0 \quad-$ & 16.3 & $8.6-27.9$ & 7.2 & $4.8-10.6$ & 7.3 & $6.3-7.8$ & 9.0 & $6.1-12.0$ \\
\hline & $\mathrm{Mn}(\mu \mathrm{g} / \mathrm{g} \mathrm{DM})$ & 148.0 & 80.4-215.6 & $134.4 \quad-$ & 212.8 & 198.8-233.6 & 150.4 & $117.6-185.2$ & 74.5 & $48.4-120.8$ & 284.4 & - \\
\hline & $\mathrm{Fe}(\mathrm{mg} / \mathrm{g} \mathrm{DM})$ & 1.6 & $0.4-2.7$ & $0.6 \quad-$ & 1.9 & $1.2-2.6$ & 1.5 & $1.3-1.7$ & 0.8 & $0.3-1.3$ & 2.2 & $0.5-3.9$ \\
\hline & & \multicolumn{2}{|c|}{ Site 1 (Typha) } & Site 1 (Phrag) & \multicolumn{2}{|c|}{ Site 2 (aerated) } & \multicolumn{2}{|c|}{ Site 2 (control) } & & & & \\
\hline \multirow{11}{*}{$\begin{array}{l}\text { Above } \\
\text { ground } \\
\text { biomass }\end{array}$} & $\mathrm{N}(\mathrm{mg} / \mathrm{g} \mathrm{DM})$ & 15.6 & & 22.2 & & 20.5 & 15.3 & & & & & \\
\hline & $\mathrm{P}(\mathrm{mg} / \mathrm{g} \mathrm{DM})$ & 2.4 & & 1.1 & & 1.3 & - & & & & & \\
\hline & $\mathrm{K}(\mathrm{mg} / \mathrm{g} \mathrm{DM})$ & 17.2 & & 11.0 & & 7.1 & 20.3 & & & & & \\
\hline & $\mathrm{Mg}(\mathrm{mg} / \mathrm{g} \mathrm{DM})$ & 1.2 & & 1.3 & & 1.3 & 1.4 & & & & & \\
\hline & Ca (mg/g DM) & 2.2 & & 3.0 & & 0.2 & 10.8 & & & & & \\
\hline & $\mathrm{Na}(\mathrm{mg} / \mathrm{g} \mathrm{DM}$ & 2.3 & & 0.9 & & 1.0 & 7.6 & & & & & \\
\hline & $\mathrm{Zn}(\mu \mathrm{g} / \mathrm{g} D M)$ & 50.0 & & 35.0 & & 80.8 & 26.7 & & & & & \\
\hline & $\mathrm{Cu}(\mu \mathrm{g} / \mathrm{g} \mathrm{DM})$ & 19.2 & & 11.8 & & 13.1 & 5.1 & & & & & \\
\hline & $\mathrm{Ni}(\mu \mathrm{g} / \mathrm{g} \mathrm{DM})$ & 9.5 & & 3.3 & & 11.8 & 10.8 & & & & & \\
\hline & $\operatorname{Mn}(\mu \mathrm{g} / \mathrm{g} D M)$ & 170.4 & & 97.2 & & 45.6 & 299.6 & & & & & \\
\hline & $\mathrm{Fe}(\mathrm{mg} / \mathrm{g} \mathrm{DM})$ & 0.3 & & 0.1 & & 0.6 & 0.2 & & & & & \\
\hline \multirow[t]{9}{*}{ Rhizomes } & $\mathrm{N}(\mathrm{mg} / \mathrm{g} \mathrm{DM})$ & 24.9 & & 24.3 & & 25.1 & 19.2 & & & & & \\
\hline & $\mathrm{P}(\mathrm{mg} / \mathrm{g} \mathrm{DM})$ & 3.1 & & 2.1 & & 1.5 & 1.5 & & & & & \\
\hline & $\mathrm{K}(\mathrm{mg} / \mathrm{g} \mathrm{DM})$ & 18.4 & & 19.4 & & 9.5 & 10.0 & & & & & \\
\hline & $\mathrm{Mg}(\mathrm{mg} / \mathrm{g} \mathrm{DM})$ & 1.5 & & 2.3 & & 0.9 & 2.5 & & & & & \\
\hline & Ca (mg/g DM) & 3.7 & & 2.9 & & 2.5 & 0.3 & & & & & \\
\hline & $\mathrm{Na}(\mathrm{mg} / \mathrm{g} \mathrm{DM}$ & 1.5 & & 7.2 & & 0.4 & 2.1 & & & & & \\
\hline & $\mathrm{Zn}(\mu \mathrm{g} / \mathrm{g} \mathrm{DM})$ & 79.6 & & 84.4 & & 130.0 & 144.0 & & & & & \\
\hline & $\mathrm{Cu}(\mu \mathrm{g} / \mathrm{g} \mathrm{DM})$ & 51.6 & & 87.6 & & 27.9 & 53.6 & & & & & \\
\hline & $\mathrm{Ni}(\mu \mathrm{g} / \mathrm{g} \mathrm{DM})$ & 13.2 & & 15.0 & & 10.7 & 19.8 & & & & & \\
\hline
\end{tabular}




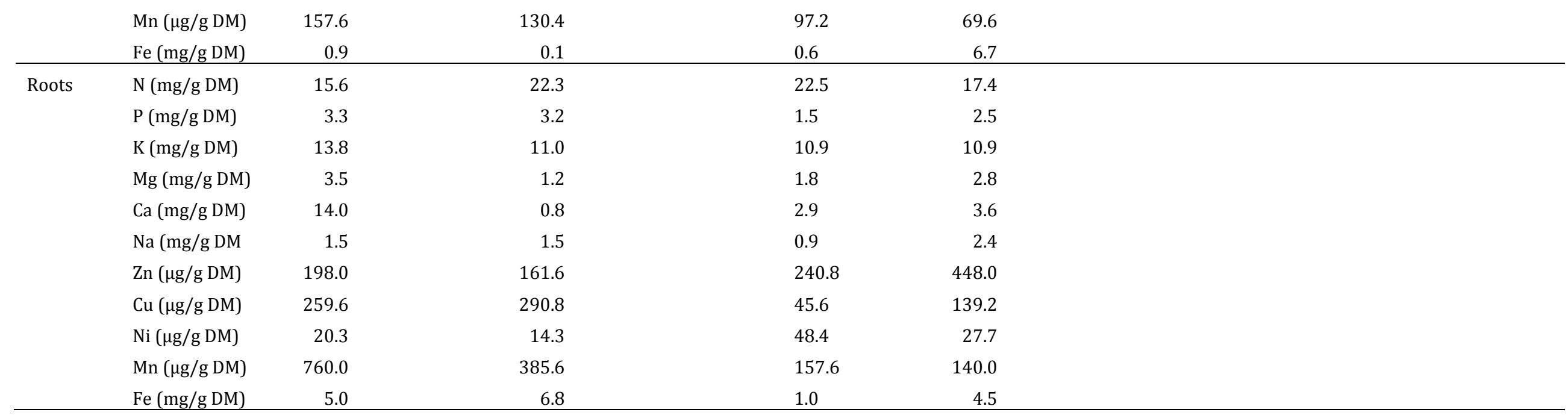

